\title{
CINE Y OTREDAD EN ELT: EDUCAR A TRAVÉS DE LAS VOCES SILENCIADAS DE BILLY ELLIOT
}

\author{
JUAN RAMÓN GUIJARRO OJEDA \\ Universidad de Granada
}

\section{RESUMEN}

En este artículo exploramos un área altamente productiva y enriquecedora dentro de la didáctica de la Lengua Inglesa. Se trata del potencial del cine para el desarrollo de la transversalidad en el aula de idiomas así como para el aprendizaje de la lengua inglesa a nivel lingüístico. También ofrecemos unas referencias teóricas sobre la transversalidad y el concepto de Otredad para encuadrar nuestra propuesta didáctica. Finalmente, realizamos una propuesta de análisis y actuación sobre aspectos de otredad, identidad o género que creemos muy beneficiosos para explotar con la película Billy Elliot en contextos de English Language Teaching.

Palabras clave: cine, otredad, transversalidad, valores, Inglés como Lengua Extranjera

\begin{abstract}
In this article we explore a highly productive and beneficial area within the general scope of ELT. We try to settle the theoretical underpinnings of the potential of films to develop cross-curricular instruction in the FL classroom at the same time students acquire communicative competence. We also offer a theoretical framework about cross-curricular education and otherness issues where to insert our practical exercises. Finally, we analyse these aspects of otherness, identity and gender in the movie Billy Elliot to foster them in EFL contexts.
\end{abstract}

Keywords: cinema, otherness, cross-curricular education, values, EFL

\section{INTRODUCCIÓN}

Este artículo está motivado por la importancia que otorga Marcel Proust (en Furstenberg, 2001: 1) a la capacidad humana de acercarse a la realidad a través de la mirada del otro cuando afirma que: "la seule véritable exploration, la seule vraie fontaine de Jouvence ne 
serait pas de visiter des terres étrangères, mais de posséder d'autres yeux, de regarder l'univers à travers les yeux des autres"; y también por el reconocimiento explícito que hace el lingüista ruso Mikhail Bakhtin (1981) sobre la importancia de posicionarse en la mirada de otra cultura para comprenderla profundamente al afirmar que: "it is only in the eyes of another culture that foreign culture reveals itself fully and profoundly ...".

El uso didáctico del cine en la enseñanza del Inglés como Lengua Extranjera tiene una larga tradición internacional (ver Allan, 1985; Tomalin, 1986; Geddes y Sturtridge, 1988, Stempleski and Tomalin, 1990; Hill, 1991; Rivers, 1994; Baddock, 1996; en Nihat, 2003). El cine en el aula de inglés es una ventana abierta al mundo, al Otro, a las diferencias y a formas diferentes de pensar, decir y hacer. Educar con el cine es una cruzada efectiva contra los dogmatismos ideológicos que se plasman en los discursos astringentes que nos invaden. Estas prácticas educativas presuponen dos acciones necesarias por parte del profesorado en el acto didáctico: 1) La reflexión continua sobre el hacer educativo; y 2) que nuestra acción didáctica sea capaz de educar, formar y enseñar en contextos difíciles de des-enseñanza, in-educación y de-formación.

La comunicación cinematográfica ofrece conexiones entre el aula y la sociedad. Las películas exploran contextos culturales que pueden ser integrados en el currículum fácilmente, son entretenidas y permiten la flexibilidad de materiales y de técnicas educativas. El cine tiene también estrechas conexiones con las experiencias personales de los estudiantes; es un foco para la interacción profesor-estudiante y puede ser utilizado para promover la conciencia de la interrelación entre imagen, movimiento, lenguaje y sonido (Word, 1995). El uso del cine en clase, de hacerse correctamente, devendrá en un incremento de la calidad en los procesos de enseñanza-aprendizaje; como afirma Post (1987), "because students live in a media-oriented world, they consider sight and sound as "user-friendly"”.

\section{OBJETIVOS DEL PRESENTE ESTUDIO}

Con el presente artículo pretendemos desarrollar una serie de objetivos de corte lingüístico, intercultural, didáctico y axiológico que podríamos sintetizar en los siguientes puntos:

- Conformar los conocimientos, destrezas y actitudes necesarios para hacer de la tolerancia ante las diferencias un valor antropológico, afectivo y educativo. El valor de la tolerancia ante las diferencias a través de la convivencia constructiva con lo que es genuinamente diferente ha de ser un proceso que no sólo se sueña, sino que hay que construirlo, lucharlo y palparlo.

- Concienciar a los estudiantes sobre la importancia de dejar de lado los reduccionismos de corte individual y social para que el 'otro' (el que es diferente por razones de género, raza, cultura, clase, orientación sexual, etc.) pueda reconocerse como valioso desde fundamentos epistemológicos, éticos y políticos.

- Fomentar el caudaloso potencial que nos ofrece el cine en el aula de ELT como uno de los mejores medios para acercar al alumnado a las diferencias que nos presenta la otredad en términos de género, identidad u orientación sexual.

- Ofrecer herramientas al profesorado de ELT sobre los constructos teóricos y prácticos que informan la transversalidad para hacer del aula de Lengua Extranjera un foro social y axiológico que vaya más allá del puro alcance lingüístico. 


\section{LA TRANSVERSALIDAD COMO MARCO DE ACTUACIÓN EN ELT}

Existe un bloque de contenidos denominados Temas transversales que aparecen por primera vez de manos de la LOGSE. Los temas transversales, en la medida en que se refieren a problemas o realidades sociales que, por su relevancia social, demandan una acción educativa de la escuela, son el verdadero campo de acción para promover un conjunto de actitudes y valores morales y éticos (Bolívar, 1995: 86; en Medina, 2002). Podemos decir, entonces, que el objetivo último de la idea de transversalidad es:

[...] proporcionar una comprensión crítica e interrelacionada de la realidad, formativa por su carácter humanista, donde el conocimiento de los conocimientos disciplinares se hace desde su complejidad/globalidad. Se aprende a relacionar los conocimientos aportados desde cada disciplina, buscando relaciones entre hechos naturales, fenómenos sociales y motivaciones personales (Bolívar, 1998: 203).

Del estudio de varios autores que han dedicado sus esfuerzos a la transversalidad (González Lucini, 1992, 1993; Rodríguez Rojo, 1995; Woods et al. 1995; Reyzábal y Sanz, 1995; Sequeiros, 1997; Yus, 1996), podemos sintetizar las características de los temas transversales en tres grupos: 1) El referente social; 2) la relación escuela-sociedad; y 3) la dimensión axiológica de la educación.

La transversalidad tiene dos grandes marcos de actuación según Villaseñor (2001): el marco sociocultural y el marco epistemológico. Por un lado, el marco sociocultural viene a constatar que los temas transversales tratan aquellos aspectos que ponen en crisis el modelo de civilización dominante. De esta forma, el sistema educativo debe proporcionar a los estudiantes los medios e instrumentos necesarios para aprehender estos cambios conceptuales a lo largo de la historia. Por el otro, dentro del marco epistemológico, los temas transversales vienen a cuestionar la concepción positivista de curriculum según la cual las áreas de conocimiento se presentan de forma fragmentada y autónoma y desprovista de valor. Ante esta situación, la transversalidad propone un modelo curricular que define la ciencia como un constructo social que permite interpretar la realidad a través de la práctica social. A partir de este proceso de reflexión/discusión, se puede reconstruir un conocimiento crítico, relevante y útil para una perspectiva transformadora.

Sin embargo, Cullen (1996; en Rubinelli 2001) apunta un problema que puede derivarse de los temas transversales como puede ser un doble desplazamiento. Por un lado, un desplazamiento de responsabilidades que exceden, por su profundidad y dimensiones y porque comprometen al sujeto y sus posibilidades de afirmarse como tal, hacia las instituciones educativas. Y por otro, un desplazamiento de temas axiológicamente valiosos, y de gran importancia para la práctica de una participación democrática crítica, a un terreno en que las diferentes áreas curriculares no se impliquen.

Son muchos los autores que apuestan por el uso de materiales transversales en el aula de idiomas (Cooper, 1993; Fredericks, Meinback y Rothlein, 1993; Lapp \& Flood, 1994; Walmsley, 1994; Willis, 1995; en Vogt, 1997). Destacan, entre otras, las siguientes ventajas:

- Permiten la interdisciplinariedad entre las distintas materias académicas.

- Se integran las cuatro destrezas comunicativas: Reading, Writing, Listening y Speaking. La exploración activa sobre un tema promueve la discusión y el uso y desarrollo de destrezas y estrategias en situaciones significativas. 
- Permiten al alumnado conectar sus conocimientos previos del mundo con su proceso de aprendizaje de la Lengua Extranjera. Se hace significativo y motivador.

- Se desarrollan destrezas tan enriquecedoras como la resolución de problemas y la toma de decisiones.

- Desde la transversalidad, podemos crear lectores y escritores activos con actitudes positivas hacia problemas sociales relevantes y hacia la lectura y la escritura.

Finalmente, nosotros añadimos que es perfecto para el desarrollo del eclecticismo educativo informado. Se pueden utilizar y combinar diferentes técnicas, métodos, textos, medios, etc.

\section{DE LA TRANSVERSALIDAD DEL CINE}

Roland Barthes afirma en La muerte del autor (1984) que:

[...] un texto no está constituido por una fila de palabras, de las que se desprende un único sentido, teológico, en cierto modo (pues sería el mensaje del Autor-Dios), sino por un espacio de múltiples dimensiones en el que se concuerdan y se contrastan diversas escrituras, ninguna de las cuales es la original: el texto es un tejido de citas provenientes de los mil focos de la cultura (p. 65) (Traducción nuestra del original francés).

El cine es, en su calidad de texto, una ventana abierta al mundo de la cultura, a las diferencias de razas, etnias, orientaciones o religiones. Es este potencial de la diversidad de las civilizaciones un aspecto que hay que tener presente a la hora de educar a las futuras generaciones.

La importancia del cine en ELT radica esencialmente en el receptor de la obra: nuestros alumnos. En la sociedad actual los estudiantes están muy familiarizados con el cine como medio narrativo artístico y que entienden y comparten y, sobre todo, forma parte de su conciencia tanto estética como lúdica. Como señala Barthes (1984)

[...] el lector es el espacio mismo en que se inscriben, sin que se pierda ni una, todas las citas que constituyen una escritura; la unidad del texto no está en su origen, sino en su destino, pero este destino ya no puede seguir siendo personal: el lector es un hombre sin historia, sin biografía, sin psicología; él es tan sólo ese alguien que mantiene reunidas en un mismo campo todas las huellas que constituyen el escrito (pp. 66-67) (Traducción nuestra del original francés).

El cine es un arte altamente transversal para el aula en el sentido que Bakhtin habla de diferentes "voces" que provienen de fuentes tan diversas como la ciencia, el arte, la religión, la clase, etc. Estas voces están integradas por palabras y por creencias y normas que se conocen como "ideología". El cine es un transmisor de ideologías y nunca estaremos fuera de la ideología porque cuando hablamos, lo hacemos con nuestra colección de lenguajes, de palabras cargadas de valores (o contravalores). Siendo así, es el sujeto social quien produce un texto que es, justamente, el espacio de cruce entre los sistemas ideológicos y el sistema lingüístico. Cuando nos referimos al cine estamos hablando de un concierto polifónico de voces.

Los signos en el cine son también ideológicos y por lo tanto debemos dudar de su inocencia a la hora de codificar la realidad. Dependen del contexto social por lo que son escurridizos, semánticamente móviles, inacabados, abiertos y dinámicos. Como afirmaba 
Bakhtin (1981), el discurso crea así el objeto-discurso en el que el cineasta (que también es un 'yo' social) aparece como mediador y en el que el espectador puede ser autor en la medida en que todos somos autores cuando hablamos, escuchamos, leemos o escribimos.

Precisamente esta heteroglosia es lo que hay que aprovechar en educación. La naturaleza de la palabra es ambigua y el lenguaje en su proyección histórica y dialógica conforman la versatilidad significativa del lenguaje. Llevando el cine al aula estamos inscribiendo el discurso de nuestros alumnos en una pragmática comunicativa.

\section{OTREDAD, EDUCACIÓN Y ELT}

El profesorado de Lenguas Extranjeras no puede permanecer impasible ante la afirmación de Julia Kristeva de que el Otro nos habita. Cathy den Thandt (comunicación personal), profesora de la Universidad de Montreal, nos comentaba en sus apasionados parlamentos sobre cine, literatura y marginalidad que los profesores de LE somos auténticos privilegiados dentro del mundo de la educación. Ninguna otra área de conocimiento se presta más fácilmente al eclecticismo, a la fusión, a la multiculturalidad y, en consecuencia, a la otredad/alteridad. Es precisamente esa falta de contenidos conceptuales determinados que guían otras materias, lo que hace el campo de la enseñanza de idiomas el melting pot idóneo para traer al aula la rica pluralidad cultural que nos rodea.

Según Flores (1999:1), la otredad es un sentimiento de extrañeza que surge cuando el ser humano se enfrenta a todo aquello que le es desconocido, resultando a menudo en el rechazo causado por el miedo a lo alieno. Aparece porque el hombre toma también conciencia de su individualidad y es consciente de que otros existen aparte de él, que están separados de él y que no son él. Estos 'otros' también existen autónomamente y pertenecen al mundo casi, podríamos decir, de lo onírico, de lo que está más allá de lo perceptible o lo imaginable.

La otredad es un fenómeno ambivalente que acompasa elementos beneficiosos y extraños: la fascinación por la novedad y la amenaza de lo familiar; o la posibilidad de la innovación y el peligro de la pérdida. Esta ambivalencia es un desafío constante para los elementos integrantes de una sociedad. Conceptualmente, se diferencia entre Otredad en el sentido de 'no-pertenencia' y Otredad en el sentido de 'desconocido/nuevo'. En el primer caso hablamos de lo social; en el segundo, de otredad cultural.

La otredad social sucede siempre que se enfatiza el hecho de que una persona no pertenece a un grupo particular. La otredad, en esta dimensión, es el resultado del establecimiento de unos patrones sociales excluyentes. Así estamos hablando de Otredad interior cuando una persona o grupo se siente excluido, o el resto de la sociedad mantiene una cierta distancia. Hay que especificar que no todas las atribuciones de la no-pertenencia se basan en exclusión formal. En la dimensión cultural, el Otro representa al desconocido cognitivamente. La experiencia de la otredad cultural nos muestra los límites de nuestra capacidad de entendimiento y las dependencias de nuestras expectativas. El desconocimiento puede ser epistémico (no entendemos algo o no lo sabemos explícitamente) o práctico (no sabemos o no podemos hacer algo).

La otredad social se resuelve con la inclusión, la otredad cultural a través del aprendizaje. Hay que señalar que la atribución y la experiencia del Otro pueden variar con las circunstancias. El Otro no es una propiedad objetiva, sino una noción relativa que varía según el contexto y las circunstancias sociales o personales. De esta forma, en la Grecia 
Clásica la homosexualidad no se enmarcaba dentro de los parámetros de la otredad y en nuestros días sí lo está.

Al contrario de lo que pudiera parecer, la exclusión es una constante más universal de lo que parece a primera vista. Castoriadis (1985) afirma "[la] aparente incapacidad de constituirse uno mismo sin excluir al otro y la aparente incapacidad de excluir al otro, sin desvalorizarlo y, finalmente, sin odiarlo". Los 'otros' siempre son representados como inferiores porque se procede a equiparar casi automáticamente a iguales e indiferenciados o, por el contrario, diferentes e incomparables. La consecuencia de no aceptar esto se reduce a no querer ver a los otros como eso, como simplemente otros; no poder dejar de compararlos; no poder simplemente aceptarlos.

La Fundación Triángulo en su Dossier Educativo 1998: Unidad didáctica sobre homosexualidad establece cuatro pasos principales a través de los cuales se intenta marginar al Otro. En primer lugar "Reducir la individualidad al grupo": no considerar a los seres humanos en su individualidad; el que es diferente se convierte automáticamente en la diferencia misma y no se le considera en su idiosincrasia personal. El segundo paso consiste en "deshumanizar al Otro"; crear imágenes falsas sobre el que es diferente (tópicos, estereotipos, miedo...). La tercera fase consiste en creer que "el Otro es peligroso" y que representa una amenaza para la sociedad (los homosexuales violan a niños, los inmigrantes nos quitan el trabajo). En última instancia viene "la agresión". Mediante la agresión, la sociedad se asegura esa limpieza de gérmenes sociales que son los Otros. Con estas actuaciones viene la violencia, el odio, la intolerancia, etc.

\section{ACTIVIDADES PARA TRABAJAR LA OTREDAD CON BILLY ELLIOT}

Los profesores de LE no debemos olvidar nunca que cuando introducimos el cine o la literatura en el aula, el primer objetivo que debemos alcanzar es el disfrute máximo de nuestros alumnos ante el encuentro con una obra de arte. Evidentemente, cuando aprendemos un idioma hay que diseñar una serie de actividades de corte estructural o comunicativo para desarrollar la competencia comunicativa. Nosotros creemos que la meta no acaba en la competencia comunicativa y damos un paso más allá para desarrollar la integridad formativa de los educandos. En el ámbito anglosajón se empieza a hablar de las life skills que dan unicidad necesaria y perspectiva axiológica a lo comunicativo. De esta forma estamos dando el salto tan necesario en la sociedad actual desde la instrucción a la educación social, la otredad y la multiculturalidad.

A continuación presentamos algunas reflexiones/motivos sobre aspectos importantes que podemos llevar a debate en el aula como actividades de desarrollo tras el trabajo más estructural, lingüísticamente hablando, con el filme Billy Elliot. Estos y otros aspectos nos ayudarán a adquirir cierto conocimiento sobre la otredad, la diferencia, las relaciones personales, sus causas, consecuencias y posibles soluciones desde la educación, la epistemología, la ética o la política.

\section{Motivo 1. Otredad, marginalidad, género y hombres homosexuales:}

Un concepto altamente asociado al de 'otredad' es el de 'marginalidad'. Flores e Yrizar (1995; en Quiróz Adame, 2003) argumentan que la marginalidad es un producto del 
principio sublime de igualdad social, ya que se pretende igualar a grupos que son muy desiguales entre sí. La marginalidad también puede ser producto de los mitos como elementos que componen los organizadores sociales; así como el componente lingüístico que posiciona a las diferentes personas dentro de la sociedad.

La marginalidad también es producto de la sociedad del patriarcado que excluye todos aquellos elementos que no encajan en los esquemas de lo masculino como género. Mujeres y homosexuales no encajan en los parámetros del patriarcado. Así, en Billy Elliot se pueden considerar aspectos de marginalidad cuando Billy quiere ser bailarín y su padre y hermano lo tachan de homosexual porque a un 'hombre' no le corresponde el rol de la danza; sino más bien el de boxeador. Como dice el padre de Billy: "Lads do football, or boxing, or wrestling. Not frigging ballet".

El sistema social asigna una serie de roles específicos a cada uno de los sexos reconocidos, y esto es lo que llamamos género según Lamas (1999): “[...] conjunto de ideas, representaciones, prácticas y prescripciones sociales que una cultura desarrolla desde la diferencia anatómica entre los sexos, para simbolizar y construir socialmente lo que es propio de los hombres 'lo masculino' y lo que es propio de las mujeres 'lo femenino'."

En nuestra cultura, las mujeres son las encargadas de todo aquello que tiene que ver con la familia, la reproducción social, sexual, cultural y religiosa de nuestras instituciones. Al hombre se le ha asignado el mundo productivo, el poder económico y político y la guerra. En Billy Elliot estos roles sociales se ven claramente representados por ejemplo en los dos profesores de actividades libres o extraescolares del colegio. El boxeo -una actividad de fuerza y lucha- es llevada a cabo por un entrenador mayor al precio de 50 peniques la sesión; mientras que la encargada de enseñar danza -un arte delicado y estético- es Mrs. Wilkinson. Cuando estas fronteras socialmente construidas y legitimadas se traspasan surgen los problemas sociales y personales relativos al género. Y las personas que lo llevan a cabo son marginadas y discriminadas por el resto del grupo como es el caso de Billy.

La homosexualidad masculina se enfrenta a una situación compleja de Otredad, ya que fluctúa entre dos polos. Por un lado, pertenecen al grupo de poder por ser hombres; y por el otro, representan la parte femenina no deseada patriarcalmente. Un homosexual es un ser altamente peligroso socialmente en el patriarcado por múltiples razones: pone en entredicho la hombría de los varones que le rodean; trasgrede los preceptos religiosos y tambalea la 'justicia' al agredir las "buenas costumbres" culturalmente establecidas.

Muy posiblemente, el padre de Billy Elliot no quiere que su hijo se dedique a la danza porque sus vecinos y la 'gente' en general van a reírse de él y van, al mismo tiempo, a sospechar del padre y del hermano por ser en ellos en quien recae el peso de la educación del pequeño Billy. Todo esto, claro está, asumiendo que Billy, por dedicarse a la danza, tuviera que ser homosexual, que no tiene razón para serlo.

\section{Motivo 2. El ejercicio del poder (guerreros, reyes, magos y amantes):}

Desde la psicología, como apuntan Moore y Gillete (1990), los modelos que constituyen el ser masculino son el de guerrero, rey, mago o amante. Cualquier otra estructura escaparía a lo aceptado socialmente y, en consecuencia, vendría la marginación. Desde el machismo se repudia la homosexualidad también por una razón que tiene que ver con el 
ejercicio del poder. Chihu (2001), comentando a Michel Foucault, establece dos relaciones básicas a partir de las cuales se sostiene el ejercicio del poder:

1.- “Contrato-opresión”: de tipo jurídico, con fundamento en la legitimidad o ilegitimidad del poder.

2.- "Dominación-represión": presentada en términos de lucha-sumisión.

De esta forma, la homosexualidad es un elemento no legitimado y por lo tanto es fenómeno de la dominación y marginación. Billy está rodeado de violencia. Ve a diario las continuas luchas de los mineros contra el gobierno de Thatcher; asiste a clases de boxeo y en su casa la situación con su padre, hermano y abuela es bastante tensa y de incomunicación. Creciendo en este contexto, no es extraño que su impotencia ante las situaciones que le rodean en la vida se exprese a través de la violencia: insulta a su padre, pega a un chico de la Royal Ballet School de Londres y pega con la almohada a la hija de la señorita Wilkinson. Además de expresarse con el baile, la violencia se convierte así en otra vía de expresión en situaciones límite de protesta tanto a las situaciones de opresión como de represión.

\section{Motivo 3. Imaginario del ser hombre y mujer:}

La diferencia sexual podemos entenderla como "una diferencia estructurante, a partir de la cual se construyen no sólo los papeles y prescripciones sociales sino el imaginario de lo que significa ser mujer o ser hombre" (Lamas, 1999). Con esto, podremos referirnos al lenguaje, las prácticas y representaciones simbólicas y los procesos inconscientes de la diferencia sexual. Así, tomaremos conciencia del imaginario del significado de ser hombre o mujer.

A Billy Elliot se le pide que sea boxeador, al igual que su abuelo y padre. Pero el chico realiza sus prácticas en el Everington Boys Club y sus ojos se vuelcan hacia la señorita Wilkinson que por cincuenta peniques da clases de ballet a un grupo de niñas de la ciudad.

Billy insiste a través de toda la película que él no es gay (un puff). Pero entonces, cabe preguntarnos cómo puede un chico proveniente de una clase trabajadora definir su masculinidad cuando sus intereses no se adecuan a las convenciones sociales. A través de toda la película, los hombres prueban diferentes métodos para probar su masculinidad. El padre y hermano de Billy afirman su masculinidad con su trabajo y sus aficiones (minería, beber, boxeo...).

\section{Motivo 4. La identidad:}

Alcoff y Potter (1993) definen identidad en los siguientes términos: "la identidad de un sujeto debe ser entendida tomando al género como un componente en interrelación compleja con otros sistemas de identificación y jerarquía". Con todos estos elementos, nos permitirán abordar el tema de la homosexualidad y su marginación social, en tanto tendrá una explicación sociológica.

En muchos momentos, es el propio Billy quien se autocensura diciéndose que los que bailan son gays en sus conversaciones con la hija de la señorita Wilkinson. Sin embargo, es esta niña quien le abre los ojos a Billy y le da ejemplos de grandes bailarines de la historia que no son gays (por ejemplo, Fred Astair). Mientras que Billy practica boxeo, se 
imagina que es un gran bailarín y emula pasos de danza con el saco de arena creando sugerentes imágenes llenas de belleza y sensibilidad. Su pasión innata por la danza le lleva a robar un libro sobre el baile y ensaya los pasos en su pequeño cuarto de baño dañándose físicamente por la falta de espacio.

Billy se cuestiona repetidas veces qué es lo que se espera de él. Esto va a ir configurando su propia identidad.

Billy Elliot tiene un amigo que es gay y se traviste. Esta situación no les impide ser amigos y la amistad sigue adelante sin producirse situaciones de relaciones sexuales. $\mathrm{He}$ aquí la controversia: el niño que baila debería ser el 'gay' y no el otro; sin embargo, es al revés. Por esta razón, esta película es un desafío claro a los límites socialmente establecidos y a los roles preestablecidos para los géneros.

\section{Motivo 5. Los significados de la homofobia:}

Según Plummer (2001) en un estudio realizado en Australia sobre los significados de la homofobia derivados del uso de insultos como poofter o faggot concluye que los significados de la homofobia son los siguientes:

- Ser infantil

- Ser flojo, débil y tímido

- Madurar despacio físicamente

- Comportarse como una chica

- Ser académico y estudioso

- Ser especial

- Ser artístico

- Aparecer diferente

- No integrarse en la cultura del grupo, ser un 'outcast' o ser solitario

- No obedecer a las expectativas del grupo

- No participar en deportes prestigiosos de equipo

- Satisfacer las expectativas de los adultos a expensas de la lealtad al grupo de iguales

- Orientación sexual

Con todo esto, se llega a la conclusión de que la homofobia tiene sus raíces en las interacciones que desde pequeños se tienen con el grupo de iguales:

[...] homophobia has its early roots in boyhood "otherness" -specifically in being different from the collectively authorized expectations of male peers, in lacking stereotypical masculinity and/or in betraying peer group solidarity. In that sense, the developmental foundations for homophobia lie in gender -in the sense of failing to measure up to "hegemonic" boys' standards than necessarily being "feminine" (Plummer, 2001:21). The converse is also true, that homophobia is often expressed in the absence of explicit knowledge of the target's sexuality (Ibíd., 21). 
Todas estas significaciones pueden ser explotadas sustancialmente con Billy Elliot y sus intenciones de ser bailarín en una sociedad patriarcal opresiva y represiva. Podemos pedir a los estudiantes que busquen todas estas características en Billy y compararlo con otros personajes de la película para analizar el grado de Otredad en los personajes de la historia.

En este respecto podemos explotar ampliamente la figura de Michael, el amigo de Billy. Éste es un chico con una apariencia andrógina y que se traviste con los vestidos de su hermana. Dice que su padre también lo hace cuando nadie lo ve en casa. Una vez más estamos ante los otros: si ser gay ya es motivo de discriminación, ser travesti es una de las manifestaciones de la homosexualidad más denostadas por el resto de la sociedad. Las muestras de intolerancia son enormes por el gran número de prejuicios que existen ante lo desconocido, los otros, los que no pertenecen a nuestro grupo. Sería este un momento muy apropiado para introducir a los estudiantes en conceptos como homosexualidad, intersexualidad, bisexualidad, lesbianismo etc; así como las respuestas sociales o temas relacionados con estos fenómenos como pueden ser la homofobia, la intolerancia, las parejas de hecho, la legislación, la salud sexual (no hablamos específicamente de SIDA, ya que estadísticamente, el $90 \%$ de las personas afectadas por este virus son heterosexuales. El problema está en hacer creer que homosexualidad y SIDA son sinónimos como estrategia para fomentar el odio hacia este colectivo).

\section{Motivo 6. La capacidad de acoger al Otro:}

Con este título es como Hélène Cixous define lo femenino. La señorita Wilkinson es capaz de acoger la alteridad de Billy Elliot y en ella recae la labor de educar a los hombres que son incapaces de comunicarse en un ambiente donde las palabras son imposibles: un padre y dos hijos. Es la señorita, el Otro-mujer en quien recae la labor de la comunicación, la educación y el diálogo entre los hombres. Pero esa voz de la profesora de baile intenta ser silenciada por un patriarcado feroz que no entiende de voces ni de miradas. De la misma forma, la abuela de Billy Elliot representa ese conato de diálogo entre los hombres, pero debido a su senilidad no es tomada en cuenta. Aquí, debemos hacer alusión también a la madre de Billy, ya muerta, que seguro habría dejado a su hijo hacer lo que sentía; así retoma el recuerdo de su madre diciendo "Mum would have let me do it".

El padre de Billy está realmente preocupado por la sexualidad de su hijo. ¿Cómo contrasta esto con la relación entre Billy y Michael a través de la película? Michael está presente en todos los momentos cruciales de la película y sería un buen ejercicio llamar la atención de nuestros estudiantes hacia aquellas escenas en las que los dos niños aparecen juntos y los roles que adoptan en las mismas.

Motivo 7. La identidad como fenómeno de integración y acción política para el cambio

Un individuo no se identifica plenamente en su existencia si no se hace partícipe consciente de que su identidad nace de la diferenciación excluyente en una cultura patriarcal. Es decir, un sujeto que no logra dar cuenta de su existencia como proceso en construcción, en una interrelación permanente con su entorno, que lo hace mutable y adaptable, es un sujeto que incide únicamente como reproductor y legitimador de la exclusión. Mientras el sujeto 
es consciente de esta realidad se hace partícipe de grupos sociales que buscan el cambio de esta relación con el entorno, e intentan modificar el origen de la exclusión a la que nos vemos sometidos. La dificultad que muestra este hecho es que la salida política en estas circunstancias, bajo los patrones culturales que nos dominan, la acción política nos tiene que llevar necesariamente a la confrontación de los sujetos sociales.

La dura situación económica en la que se halla sumergido el condado de Durham, no es precisamente el mejor contexto donde poder desarrollarse profesionalmente como bailarín, ni incluso como un simple aficionado si eres un niño y tu familia está formada por un padre y hermano mayor que trabajan en la minería (en huelga contra el gobierno) y una abuela que se hunde en la senilidad. Además, sobre esta situación de extrema esterilidad planea la ausencia de una madre y una esposa muerta recientemente. Billy Elliot es el Otro, tanto porque no pertenece al grupo en el que vive, como que también representa la novedad en el grupo. Estas situaciones le llevan a la marginalidad.

El padre y hermano de Billy son también al mismo tiempo Otros. Ellos representan la otredad en su calidad de diferencia de clase. Luchan contra el gobierno que los oprime en su trabajo en las minas y también contra los esquiroles que apoyan al gobierno. Estos personajes deben ser analizados de forma profunda porque reúnen en el mismo sujeto el ser que excluye y el ser excluido.

Billy Elliot, por su lado, es obligado a encontrar, como sujeto social excluido, nuevas formas de socialización que requieren del uso de nuevos códigos del lenguaje en una tarea contracultural altamente desafiante. Es a través de estas nuevas concepciones sobre el género y el lenguaje que es posible el cambio de la cultura patriarcal, es decir, la creación de un sistema que nos lleve a reconocer en la otredad la misma dignidad individual y social de que goza lo masculino.

\section{Motivo 8. Las voces silenciadas de las minas}

Los mineros del condado de Durham representan a otro grupo oprimido y reprimido socialmente. En 1984, el gobierno de Margaret Thatcher se enfrenta a una de las mayores crisis de su existencia con la rebelión de los trabajadores de las minas en el Noroeste de Inglaterra. La respuesta más inmediata por parte de la Dama de Hierro es silenciar esas voces, descargar sobre ellas el duro peso de la policía.

Son tiempos duros para los Elliot y la huelga de mineros, como bien indica la película, no ofrece ninguna esperanza a los trabajadores. Jackie y Tony (padre y hermano mayor de Billy) luchan a diario en una batalla que está perdida de antemano para proteger su modo de vida y sobre todo, su dignidad. En este contexto aparece Billy y su ballet -una intrusión muy peligrosa en el sentido que ellos tienen de la masculinidad.

La situación económica es tan dura que antes de volver a las minas, el padre de Billy prefiere romper el piano para hacerlo leña para el fuego. Billy contempla la estremecedora escena mientras recuerda que ese piano -símbolo del arte y de la libertad-pertenecía a su madre ahora muerta.

La imagen más conmovedora y metafórica es la de la vuelta de los mineros al duro trabajo de la extracción del carbón. Los mineros se introducen en un ascensor y el capataz les cierra la puerta de rejas. Todos los mineros permanecen en silencio, vencidos y reprimidos. Una vez más sus voces no han sido escuchadas y los grupos de poder han impuesto sus condiciones. 


\section{CONCLUSIONES}

Debemos tender hacia una educación que apele al valor antropológico de la afectividad, la emotividad o la fantasía para conformar conocimientos, destrezas y actitudes que hagan que la vida en conjunto sea más grata para todos. Debemos dejar de lado los reduccionismos de corte individual y social para que la humanidad vea al Otro como un ser diferente que expresa su subjetividad a través de un ethos absolutamente diferente al nuestro, aunque absolutamente valioso como el nuestro. La aceptación del Otro debe pasar por los filtros no sólo de la epistemología, sino de la ética y de la política.

Evocando a Morin y Kern (1993), no se trata de tolerar lo que se considera distante de la normalidad, sino de convivir constructivamente con lo que es genuinamente diferente. Una educación en y para la diferencia es el desafío que la humanidad deberá afrontar en el futuro para poder vencer inveterados conflictos e injusticias sempiternas. La diversidad no sólo se sueña, sino que hay que construirla, lucharla y palparla.

A través del análisis llevado a cabo en este artículo sobre aspectos de otredad e identidad en la película Billy Elliot, ha quedado evidenciado el gran potencial que ofrece el cine en habla inglesa al profesorado de ELT. El cine es un instrumento cercano y motivador para los estudiantes que, precisamente debido a esa cercanía, conecta perfectamente con sus intereses y sus discursos y es el mejor medio para acercar al alumnado a las diferencias que nos presenta la otredad en términos de género, identidad u orientación sexual. También hemos presentado al profesorado de ELT una serie de bases teóricas y prácticas que le permitirán desarrollar los postulados de la transversalidad tal y como se contemplan en la legislación educativa vigente.

No podríamos terminar este artículo sin acudir a refugiarnos en las sabias palabras de Julia Kristeva cuando afirma que: "Extrañamente,/ el extranjero nos habita:/es la cara oculta de nuestra identidad,/ el espacio que estropea nuestra morada/ el tiempo que arruina la comprensión y la simpatía./ Si lo reconocemos en nosotros,/ lograremos no detestarlo en sí mismo./ Y este síntoma convierte precisamente el "nosotros" en problemático,/ tal vez imposible:/ el extranjero empieza cuando surge la conciencia de mi diferencia/ y termina cuando todos nos reconocemos extranjeros,/ rebeldes ante los lados y las comunidades".

\section{REFERENCIAS BIBLIOGRÁFICAS}

Alcoff, L. y E. Potter, 1993. Feminist Epistemologies. New York: Routledge.

Almaguer, T. 1995. «Hombres chicanos: Una cartografía de la identidad y del comportamiento homsexual». Debate feminista, 11, abril 1995.

Allan, M. 1985. Teaching English with video. Avon: Longman.

BADDOCK, B. 1996. Using Films in the English Class. Hemel Hempstead: Phoenix, ELT.

Bakhtin, M. M. 1981. The Dialogic Imagination. C. Emerson \& M.Holquist, Trans. Austin: University of Texas Press.

BARthes, R. 1984. «La mort de l'auteur». En Le bruissement de la langue. Paris : Editions du Seuil.

Bolívar Botía, A. 1995. La evaluación de valores y actitudes. Madrid: Anaya. 


$$
\text { Anaya. }
$$

CAstoriadis, C.1985. «Reflexiones en torno al racismo». En Memorias del Coloquio 'Inconsciente y cambio social'. Paris: Association pour la Recherche e l'Intervention Psichologique.

COOPER, J. D. 1993. Literacy: Helping children construct meaning. Boston: Houghton Mifflin Company.

Cullen, 1996. «Los contenidos transversales. Cuestión política, problema ético, desafío didáctico». En Jornadas de formación ética y ciudadanía. Salta: Unsa

Chiнu, A. A. 2001. El concepto de poder en Foucault. Méjico: Siglo XXI.

Flores, O. 1999. «Octavio Paz: La otredad, el amor y la poesía». Razón y palabra. No 15, año 4, Agosto-Octubre.

Flores, V. E. y H. Yrizar Rojas, 1995. «La marginalidad ¿un constructo del lenguaje», En Quiroz Adame, A. 2003. «Marginalidad del hombre homosexual». En <http:// www.dicuagro.org/revista/tenocelome1/ensayos/ensay3/index.htm $>$. Fecha de acceso: 9 de diciembre de 2003

Fredericks, A., A. MeInBach y L. Rothlein, 1993. Thematic units: Anintegrated approach to teaching science and social studies. New York:HarperCollins.

Fundación Triángulo, 1998. Dossier Educativo 1998: Unidad Didáctica sobre homosexualidad. Madrid: UD.

FurstenBerg, G. et al. 2001. «Giving a virtual voice to the silent language of culture: the Cultura project». Language Learning \& Technology, Vol. 5, No. 1, pp. 55-102.

Geddes, M. y G. Sturtridg, eds. 1988. Video in the Language Classroom.Oxford: Heinemann.

GonZÁlez LucinI, F. 1992. Educación en valores y diseño curricular. Madrid:Alhambra Longman.

- F. 1993. Temas transversales y educación en valores. Madrid: Centro de apoyo para el desarrollo de la reforma educativa.

HiLl, B. 1991. Making the Most of Satellites and Interactive video. London: Centre for Information on Language Teaching and Research.

KRISTEVA, J.1991. Strangers to Ourselves. New York: Columbia U. P.

Lamas, M. 1999. «Género, diferencia de sexo y diferencia sexual». Debate Feminista. Vol. 10, Octubre 1999. Méjico D. F.: Impretei.

LAPP, D. y J. FloOD, 1994. «Integrating the curriculum: First steps». The Reading Teacher, 47 (5), 416-419.

Medina Rivilla, A. y F. Salvador Mata. 2002. Didáctica general. Madrid: Prentice Hall.

Moore, R. y D. Gillete. 1993. La crisis del Proceso Ritual Masculino. Barcelona: Ediciones Piados Ibéria, S.A.

Morin, E. y A. B. Kern.1993. Tierra Patria. Buenos Aires: Nueva Visión. 
Nihat Eken, A. 2003. «'You've got mail’: a film workshop». ELT Journal. Volume 57/ 1. January 2003. pp. 51-59.

OchоA, A. 2000. «¿Machismo Gay?». Desnudarse, 11, Septiembre. Caledón Editoriales.

PlummER, D. C. 2001. «The quest for modern manhood: masculine stereotypes, peer culture and the social significance of homophobia». Journal of Adolescence, 24, 15-23.

Post, L. W. 1987. «Frankly, My Dear». English Journal, 76 (1), 28-30.

Quiroz Adame, A. 2003. «Marginalidad del hombre homosexual». En <http:// www.dicuagro.org/revista/tenocelome1/ensayos/ensay3/index.htm $>$. Fecha de acceso: 9 de diciembre de 2003

Reyzábal, M. y A. I. SAnz, 1995. Los ejes transversales. Aprendizajes para la vida. Madrid: Escuela Española.

Rivers, W. M. (Ed.). 1994. Interactive Language Teaching. Cambridge: Cambridge University Press.

RodríGuez Rojo, M. 1995. La educación para la paz y el interculturalismo comotema transversal. Barcelona: Oikos Tau.

RuBINELLI, M. 2001: «Interculturalidad y transversalidad: reflexiones para pensar sus vinculaciones». Kairós. Año 5, (8), $2^{\circ}$ semestre.

SEQueIros, 1997. Educar para la solidaridad. Barcelona: Octaedro.

Stempleski, S. y B. Tomalin, 1990. Video in Action. London: Prentice Hall International.

Tomalin, B. 1986. Video, TV and Radio in the English Class. London: Macmillan.

ViLlasEÑor García, M. L. 2001: «Temas transversales en la escuela y otros ámbitos». La tarea: revista de educación y cultura. En http://www.latarea.com/mx/ articu/ articu15/villas15.htm. Fecha de acceso: 5 de diciembre de 2003

Vogh, M. E. 1997. «Cross-curricular thematic instruction». En <http:// www.eduplace.com/rdg/res/vogt.html>. Fecha de acceso: 5 de diciembre de 2003

Walmsely, S. 1994. Children exploring their world: Theme teaching in elementary school. Portsmouth, NH: Heinemann.

WiLLis, S. 1995. «Refocusing the curriculum: Making interdisciplinary efforts work».ASCD Education Update, 37 (1), 1-8.

Wood, D. J. 1995. «Good video movies for teaching English as a Foreign or Second Language». Bulletin of the International Cultural Research Institute of Chikushi Jogakuen College, 6, 105-125.

Woods, P. y M. HAMmersley (eds.) 1995. Género, cultura y etnia en la escuela. Informes etnográficos. Barcelona: MEC/Paidós.

Yus Ramos, R. 1996. Temas transversales: Hacia una nueva escuela. Barcelona: Graó. 